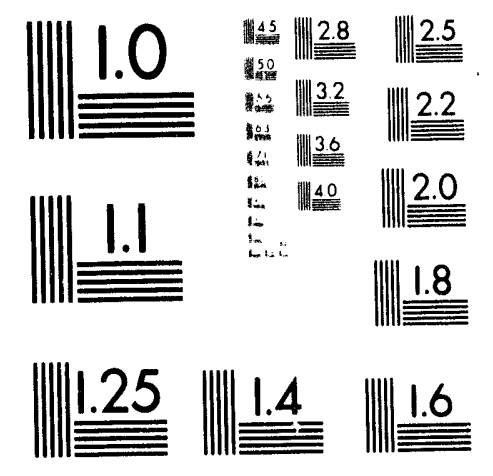



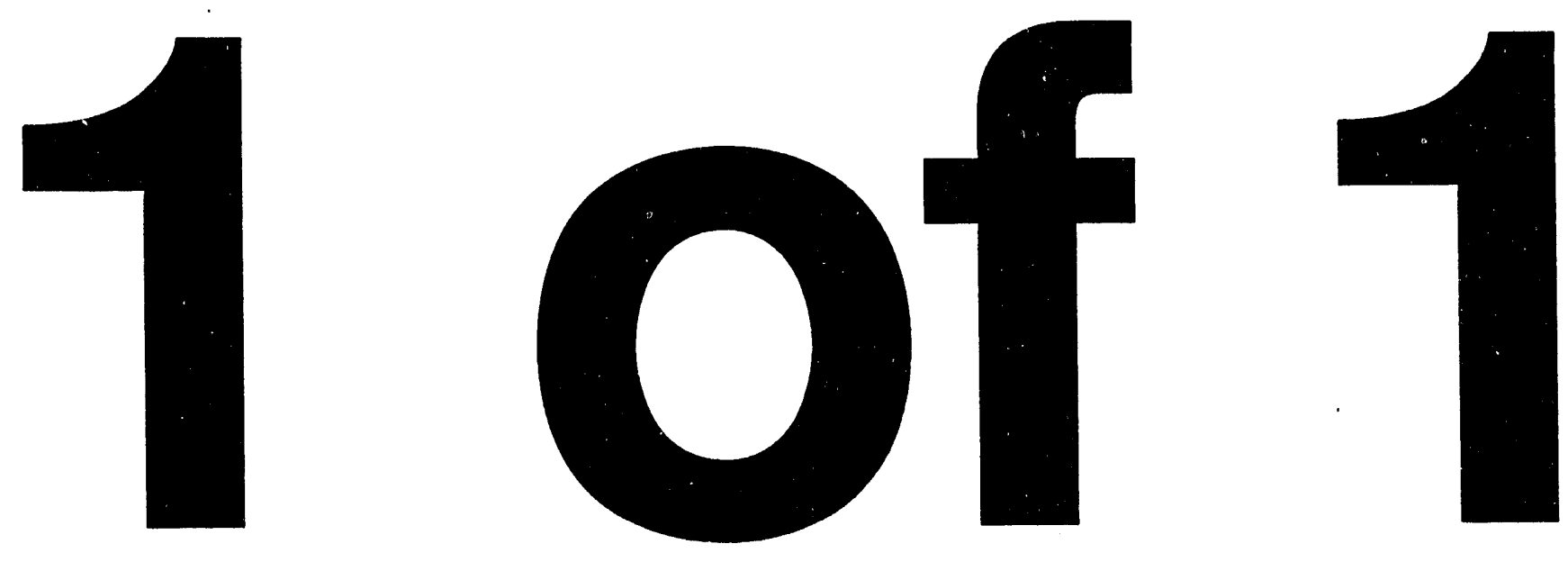


\title{
SHORT WAVELENGTH FELS USING THE SLAC LINAC*
}

\author{
H. Winick, K. Bane, R. Boyce, J. Cobb, G. Loew, P. Morton, H.-D. Nuhn, J. Paterson, P. Pianetta, T. Raubenheimer, \\ J. Seeman, R. Tatchyn, V. Vylet \\ Stanford Linear Accelerator Center, Stanford University, Stanford. CA 94309. \\ C. Pellegrini, J. Rosenzweig. G. Travish \\ Department of Physics, University of California (UCLA), Los Angeles, CA 90024. \\ D. Prosnitz, E. T. Scharlemann \\ Lawrence Livermore National Laboratory, Livermore, CA 94550. \\ K. Halbach, K.-J. Kim, R. Schlueter, M. Xie \\ Lawrence Berkeley Laboraton;, University of California, Berkeley, CA 94720. \\ R. Bonifacio, L. De Salvo, P. Pierini \\ Dipartimento di Fisica dell'Università di Milano and INFN, Via Celoria 16, 20133 Milano, Itaby.
}

\begin{abstract}
Recent technological developments have opened the possibility to construct a device which we call a Linac Coherent Light Source (LCLS)[1-4]; a fourth generation light source, with brightness, coherence, and peak power far exceeding other sources. Operating on the principle of the free electron laser (FEL), the LCLS would extend the range of FEL operation to much shorter wavelength than the $240 \mathrm{~nm}$ that has so far been reached. We report the results of studies of the use of the SLAC linac to drive an LCLS at wavelengths from about $3-100 \mathrm{~nm}$ initially and possibly even shorter wavelengths in the future. Lasing would be achieved in a single pass of a low emittance, high peak current, high energy electron beam through a long undulator. Most present FELs use an optical cavity to build up the intensity of the light to achieve lasing action in a low gain oscillator configuration. By eliminating the optical cavity, which is difficult to make at short wavelengths, laser action can be extended to shorter wavelengths by Self-Amplified-Spontaneous-Emission (SASE), or by barmonic generation from a longer wavelength seed laser. Short wavelength, single pass lasers have been extensively studied at several laboratories and at recent workshops $[5,6]$.
\end{abstract}

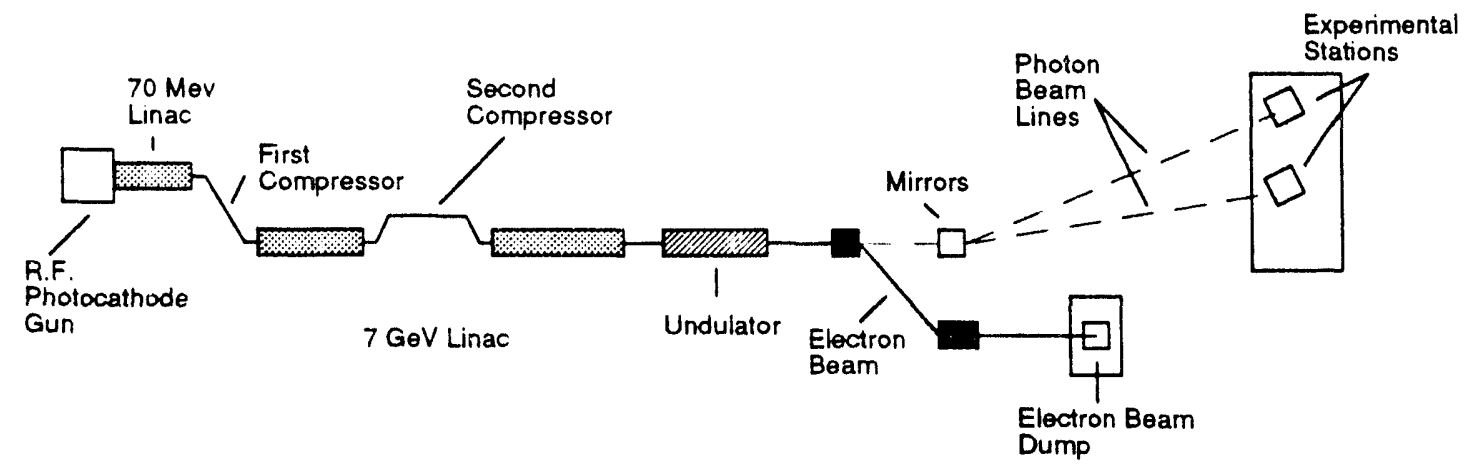

Fig. 1: LCLS overview.

The required low emittance electron beam can be achieved with recently developed RF photocathode electron guns [7]. The peak current is increased by about an order of magnitude by compressing the bunch to a length of about $0.2 \mathrm{ps}$ (ms). Techniques for beam transport, acceleration, and compression without emittance dilution have ieen developed at SLAC as

\footnotetext{
* Supported in part by the Department of Energy, Office of Basic Energy Sciences and High Energy and Nuclear Physics and Department of Energy Contract DE-AC03-76SF0015. 
par of the linear collider project [8]. The undulator length required to saturate the laser varies from about $15 \mathrm{~m}$ for a $100 \mathrm{~m}$ FEL to about $60 \mathrm{~m}$ at $3 \mathrm{~nm}$. Initial experiments, at wavelengths down to about $50 \mathrm{~nm}$, are planned using the $25 \mathrm{~m}$ long Paladin undulator now located at LLNL. In a proposed future LCLS R\&D facility the shor wavelength light pulses are distributed to multiple end stations using grazing incidence mirrors. About $10^{14}$ photons per pulse can be produced at a $120 \mathrm{~Hz}$ rate, corresponding to average brightness levels of about $10^{21}$ photons $/ \mathrm{s} / \mathrm{mm}^{2} / \mathrm{mrad}^{2}$ within $0.1 \%$ BW and peak brightness levels of about $10^{31}$ photons $/ \mathrm{s} / \mathrm{mm}^{2} / \mathrm{mrad}^{2}$ within $0.1 \% \mathrm{BW}$. Peak power levels are several hundred megawatts to several gigawatts. Electron energies required range from about $500 \mathrm{MeV}$ for the $100 \mathrm{~nm}$ FEL to about 7 $\mathrm{GeV}$ for $3 \mathrm{~nm}$.

\section{INTRODUCTION}

Two recent developments have opened the possibility of constructing linac-based $x$-ray lasers operating at shor wavelengths. First, at Los Alamos (and elsewhere) RF photocathode guns have been shown to deliver low emittance (3-4

Table 1: Approximate performance parameters of the LCLS at $4 \mathrm{~nm}$.

\begin{tabular}{|l|l|}
\hline Electron energy & $7 \mathrm{GeV}$ \\
\hline Bunch charge & $1 \mathrm{nC}$ or $6 \times 10^{9} \mathrm{e}^{-}$ \\
\hline Electron beam emittance (normalized) & $3.5 \mathrm{~mm}$-mrad \\
\hline Bunch length (rms) & $30 \mu \mathrm{m}$ \\
\hline Peak current & $2500 \mathrm{~A}$ \\
\hline Peak coherent power & $10 \mathrm{GW}$ \\
\hline Average coherent power & $0.4 \mathrm{~W}$ \\
\hline Pulse width (rms) & $130 \mathrm{fs}$ \\
\hline Coherent photons / pulse & $5 \times 10^{13}$ \\
\hline Coherent energy / pulse & $3 \mathrm{~mJ}$ \\
\hline Repetition rate & $120 \mathrm{~Hz}$ \\
\hline Bandwidth (ms) & $0.1 \%$ \\
\hline Peak brightness & $>10^{31 *}$ \\
\hline Average brightness & $>10^{21 *}$ \\
\hline Photon beam diameter at $50 \mathrm{~m}$ & $2 \mathrm{~mm}$ \\
\hline Beam divergence & $10^{-5} \mathrm{radians}$ \\
\hline *photons/s/rnm $2 / \mathrm{mrad}^{2}$ within $0.1 \%$ & $\mathrm{BW}$ \\
\hline
\end{tabular}
$\mathrm{mm}$-mrad normalized), high charge (> $1 \mathrm{nC}$ ) electron beams. Second, the successful operation of the Stanford Linear Collider (SLC) [8] has demonstrated that we now have available the tools, understanding, and techniques needed to transport, accelerate, and compress electron bunches with little dilution of phase space. These developments make it possible to deliver electron beams with phase space densities sufficient to drive shor wavelength lasers. With present technology, wavelengths down to about $3 \mathrm{~nm}$ appear achievable. With improvements to components and with experience at these wavelengths, even shorter wavelengths possibly down to $0.1 \mathrm{~nm}$. may be reached.

We propose an LCLS R\&D facility aimed at the development of linac-driven, shor wavelength $x$-ray lasers, ard their scientific and technological utilization. The main performance parameters are listed in table 1 and an overview is shown in fig. 1. After commissioning, the first laser would operate starting at a wavelength of about $10 \mathrm{~nm}$ and then be pushed down to about $3 \mathrm{~nm}$. With more extensive $R \& D$, along with the use of higher energy electrons, additional undulators, and the development of improved RF guns, it is expected that this facility could achieve (with additional funding) a laser operating at even shorter wavelengths, possibly in the $0.1 \mathrm{~nm}$ regime.

Many facilities at SLAC make it an attractive site for the LCLS. The $50 \mathrm{GeV}$ linac is operational. Many beam diagnostics are installed and functional. An enclosure to bouse the undulator exists at the end of the SLAC linac. This enclosure is the Final Focus Test Beam (FFTB) which was completed in 1993 for $R \& D$ associated with final focus systems for future linear colliders. There is sufficient space in the FFTB housing to accommodate the LCLS undulator. After a small upgrade, the FFTB enclosure would provide adequate shielding for beams delivered alternately to both facilities. The LCLS photon beams emerge into the SLAC research yard, about $125 \mathrm{~m}$ from the SSRL beam lines on SPEAR. Thus, it is possible to bring beams from the LCLS and SPEAR to the same sample chamber for pump-probe experiments. 
Table 2: Performance comparison of the LCLS with ALS and APS at $4 \mathrm{~nm}$.

\begin{tabular}{|l|c|c|l|}
\hline & APS & ALS & LCLS \\
\hline Average Beam Current [mA] & 100 & 400 & $1.2 \times 10^{-4}$ \\
\hline$B_{\text {peak }}\left[10^{21 *}\right]$ & 0.66 & 9.2 & $7 \times 10^{10}$ \\
\hline$B_{\text {ave }}\left[10^{17} *\right]$ & 4.3 & 200 & $3 \times 10^{4}$ \\
\hline$P_{\text {peak }}[\mathrm{W}]$ & 0.13 & 1.8 & $1 \times 10^{10}$ \\
\hline$P_{\text {ave }}[\mathrm{mW}]$ & 0.1 & 4.3 & $4 \times 10^{2}$ \\
\hline $\mathrm{N}_{\text {ph,peak }}\left[10^{6} / \mathrm{pulse}\right]$ & 0.3 & 1 & $5 \times 10^{8}$ \\
\hline $\mathrm{N}_{\text {ph,ave }}\left[10^{11} / \mathrm{s}\right]$ & 19 & 860 & $6 \times 10^{5}$ \\
\hline$* \frac{\mathrm{photons}_{\text {sec }} \mathrm{mm}^{2} \cdot \mathrm{mrad}^{2} \cdot 0.1 \% \mathrm{BW}}{}$ & & \\
\hline
\end{tabular}

The proposed LCLS operates on the principle of the FEL, but does not need an optical cavity which is difficult or impossible to make at such short wavelengths. Instead, $x$-ray laser operation is achieved in a single pass of an electron beam through the long undulator by Self-Amplified-Spontaneous-Emission (SASE), or by harmonic generation from a longer wavelength seed laser. Although the theory of these processes is well developed, there is little experimental data with which to compare, since most FELs have used oscillator cavities. It is therefore important to make detailed comparisons between experiment and theory, for example to verify the accuracy and wavelength dependence of simulation cotes and assumptions about startup from noise. In the proposed $R \& D$ facility we plan to do this initially at wavelengths around $10 \mathrm{~nm}$ or longer, where certain tolerances are more manageable. As experience is gained and tighter tolerances are met, operation down to $3 \mathrm{~nm}$ can be expected, still using electrons below the $10 \mathrm{GeV}$ that will be available.

From table 2 the average values of the brightness and coherent power are more than two orders of magnitude greater than that projected for undulators on 3rd generation light sources such as the ALS (see fig. 2). Peak values are more than nine orders of magnitude

higher. Photon beams with this extraordinarily high brightness, coherence, and peak power will make possible a wide range of experimental studies in many scientific and technical fields iucluding $x$ ray imaging of biological specimens in and around the "water window" (including producing $\mathrm{x}$-ray holograms of live biological specimens in a single sub-picosecond pulse), time resolved studies of condensed matter systems and chemical reaction dynamics, and non-linear processes. Because the properties of this light source go many orders of magnitude beyond that available from any other source in operation or construction, it is likely that entirely new scientific applications will be opened. Exploratory experiments will be carried out on two diagnostic / experimental stations. With two experiments able to receive pulses, techniques will be developed for rapid switching of the beam, as well as rapid changing of the beam parameters such as wavelength and intensity to meet different experimental conditions. An FY1996 Short Form Construction Project Data Sheet has been submitted to DOE for this project. The total estimated cost is $\$ 29.45 \mathrm{M}$.

Also described in this report are plans for "demonstration" experiments (using the $25 \mathrm{~m}$ long PALADIN undulator [9] now at LLNL), at wavelengths around $100 \mathrm{~nm}$, to gain experience as early as possible and to increase confidence that the shorter wavelength sources will work as expected.

\section{TECHNICAL COMPONENT}

The main technical components of the proposed LCLS R\&D Facility (see fig. 1) have been described in detail in previous reports. They are a high-brightness, laser-driven, RF electron gun with a photocathode [7];

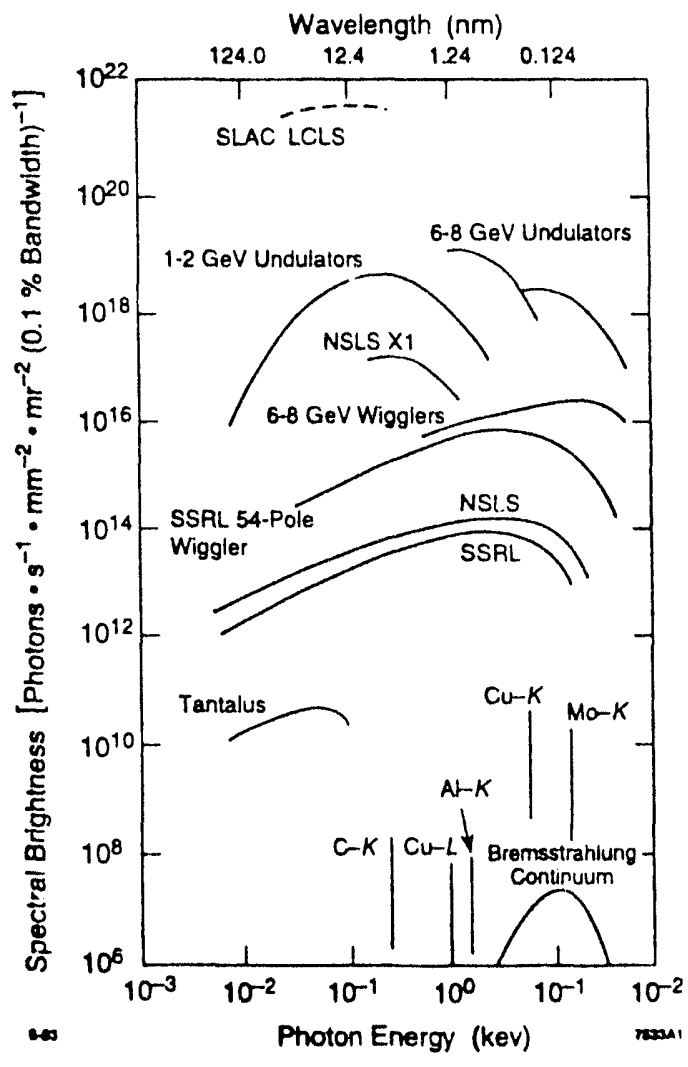

Fig. 2: Spectral brightness of synchrotron radiation sources and the SLAC LCLS. 


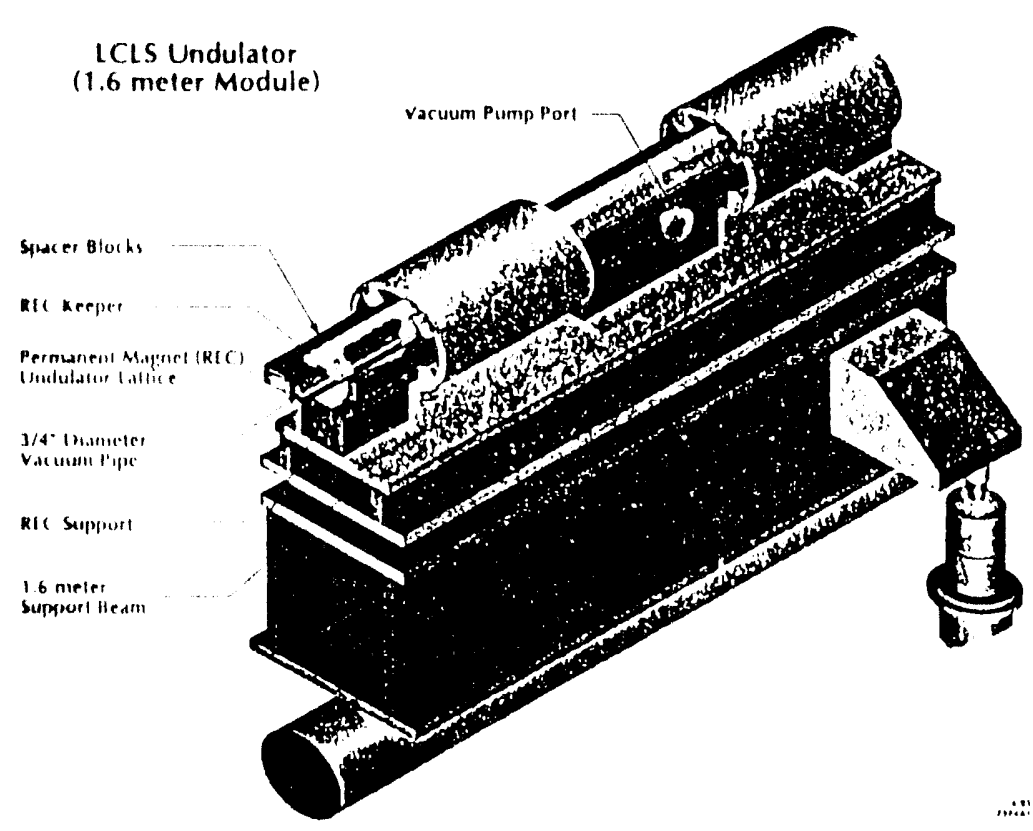

Fig. 3: LCLS undulator

two electron bunch length compressors [10]: the exusting SLAC linac: beam diagnostics: a long undulator combined with a FODO quadrupole focusing system [11]; a photon beam deflecting mirror system, photon beam lines, and experimental end stations [12]. The RF gun. to be installed about $1 \mathrm{~km}$ from the end of the SLAC linac, would produce a single bunch of $6 \times 10^{9}$ electrons with an invariant emittance of about $3.5 \mathrm{~mm}-\mathrm{mrad}$ and a bunch length of about $500 \mu \mathrm{m}(\mathrm{mms})$. That bunch is then accelerated to 70-100 $\mathrm{MeV}$ and compressed to a length of about $200 \mu \mathrm{m}$. The main SLAC linac accelerates the bunch to about $2 \mathrm{GeV}$. where a second bunch compressor reduces the length to $30-40 \mu \mathrm{m}$ resulting in a peak current of $2-3 \mathrm{kA}$. The electron bunch is then accelerated to 7 . $8 \mathrm{GeV}$, transported through a $50-70 \mathrm{~m}$ long undulator, and then deflected to a beam dump. The light pulses emerging from the long undulator are distributed to multiple user stations using grazing incidence mirors. Opumized parameters and tolerances for bunch compression and acceleration [10] and the FEL performance [13] have been studied

\section{UNDULATOR}

Based on 2D simulations, the following paramcier set has been established for the LCLS undulator: a) period $=8 \mathrm{~cm}, \mathrm{~b}$ ) peak magnetic field $=0.8 \mathrm{~T}$. $\mathrm{c}, \mathrm{K}=6$, d) total length $=60 \mathrm{~m}$. e) focusing betatron wavelength $=60 \mathrm{~m}$, and $\mathrm{f}$ ) gap $=1.5 \mathrm{~cm}$. A pure permanent magnet (1.e. no steel poles) design [11] was chosen primarily to allow a superimposed focusing (FODO) quadrupole lattice to be used to provide the necessary strong iocusing of the electron beam. In vier, of the 60 $m$ length, a segmented support structure for the magnet and vacuum transpor system has been designed. This consists of ten $6.4 \mathrm{~m}$ sections. each consisting of a girder supporting four $1.6 \mathrm{~m}$ modules on adjustable supports. The focusing lattice consists of seventy-five $40 \mathrm{~cm}$ long. $15 \mathrm{~T} / \mathrm{m}$ quadrupoles placed at $80 \mathrm{~cm}$ intervals. A schematic view of the minimum $1.6 \mathrm{~m}$ module with selected component callouts, including the quadrupole focusing yokes, is shown in fig. 3. A list of parameter values describing both the quadrupole and primary magnet lattices is given in table 3 .

Table 3: Parameters of the LCLS undulator and FODO quadrupole lattice.

\begin{tabular}{|l|c|l|c|}
\hline \multicolumn{2}{|l|}{ Permanent magnet lattice parameters } & \multicolumn{2}{|l|}{ FODO quadrupole lattice parameters } \\
\hline$\lambda_{u}$ (Undulator period) & $8 \mathrm{~cm}$ & Quad aperture radius & $6 \mathrm{~cm}$ \\
\hline$\lambda_{\mu}$ (PM block penod) & $2 \mathrm{~cm}$ & Quad outside diameter & $20 \mathrm{~cm}$ \\
\hline $\mathrm{h}$ (PM block height) & $1.9 \mathrm{~cm}$ & Quad length & $40 \mathrm{~cm}$ \\
\hline $\mathrm{w}$ (PM block length) & $4 \mathrm{~cm}$ & Quad gradient & $15 \mathrm{~T} / \mathrm{m}$ \\
\hline $\mathrm{g}$ (Undulator gap) & $1.5 \mathrm{~cm}$ & FODO period & $1.6 \mathrm{~m}$ \\
\hline $1 \quad \begin{array}{c}\text { (PM block width in } \\
\text { the z direction) }\end{array}$ & $1.9 \mathrm{~cm}$ & Phase advance per cell & $11.5 \mathrm{degrees}$ \\
\hline $\mathrm{B}_{\mathrm{r}}$ & $1.08 \mathrm{~T}$ & Total power budget & $300 \mathrm{~kW}$ \\
\hline
\end{tabular}

\section{BEAM LINES}

Due to the extreme brevity and peak intensity of the LCLS output radiation, special emphasis has been placed on the design of the photon beam line system [12]. To minimize the likelihond of sustaining component damage at the expected 
$10^{12} \mathrm{~W} / \mathrm{cm}^{2}$ peak power densities at normal incidence, a deflection scheme utilizing solid-state mirrors at grazing incidence has been developed. An initial concept of this mirror system can be seen in fig. 4. Furthermore, the necessity of maintaining high reflectivity to avoid peak-power damage leads to the need for an ultra-high vacuum environment with the provisions for in-situ cleaning of all the reflecting surfaces. To exploit the diffraction-limited source size of the LCLS, the use of a simple monochromator configuration utilizing a single grating in a conical diffraction geometry, with the source as the effective entrance slit, is under consideration.

\section{DEMONSTRATION EXPERIMENT - SASE Examples}

A longer wavelength $(40-360 \mathrm{~nm})$ demonstration experiment using the SLAC Linac is being considered to test the beam manipulation and lasing by SASE and harmonic generation. The proposed scheme is designed to permit quasi-parasitic

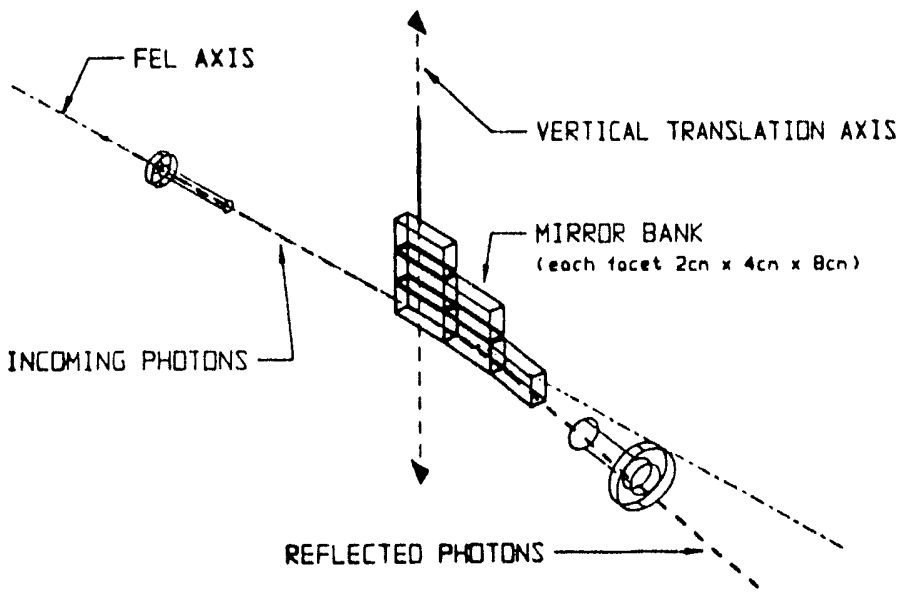

Fig. 4: Multiple mirror system for LCLS optical beams. operation at a few hertz rates during fixed target, $120 \mathrm{~Hz}$ runs in End Station A at SLAC. Emphasis is placed on the use of existing hardware, primarily the $25 \mathrm{~m}$ long PALADIN undulator [9] at LLNL. The required components would be installed at SLAC in a few brief downtimes.

The studies made possible by this demonstration would be: 1) electron beam dynamics of double bunch compression and acceleration, 2) SASE laser startup as a function of electron beam charge, density, energy, and energy spread, 3) SASE temporal, spectral composition and fluctuations [14], 4) power saturation effects including tolerances and steering, and 5) achieving short wavelengths by harmonic generation from a $240 \mathrm{~nm}$ input seed laser. This FEL demonstration experiment would be located early in the SLAC linac (Sectors 1 and 2) where the ordinary beam energy is low. The experiment would be parasitic to the $120 \mathrm{~Hz}$ straight ahead "End Station A" runs which operate for about 3 months per year. Thus, the linac quadrupole lattice need not be changed from the primary beam progran. The beam would be injected into the FEL at about $1 \mathrm{~Hz}$ (or more) using pulsed magnets to inject and extract the beam from the linac.

A schematic view of this demonstration experiment is shown in fig. 5. The beam is generated in an RF photocathode gun, which is driven by "load" power from existing klystrons and accelerating structures in the first $100 \mathrm{~m}$ of the SL.AC linac (Sector 1). A single bunch of $1 \mathrm{nC}$ is made in the gun, accelerated to about 70-100 MeV, and injected into the Sector 1

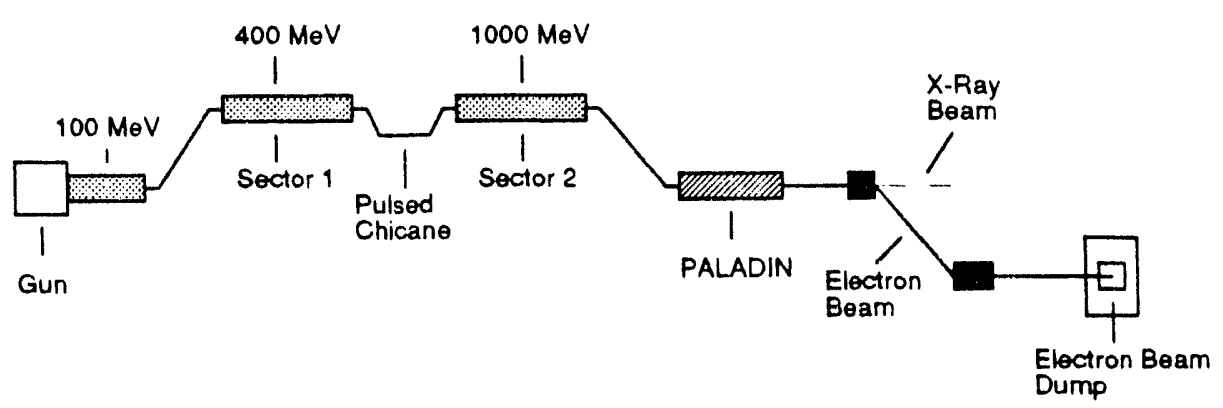

Fig. 5: Schematic overview of the demonstration experiment..

accelerator using the last bend magnet in the "SLC positron injection chicane" in early Sector 1 . The first bunch length compression is done in this injection process. After acceleration to about $300-500 \mathrm{MeV}$, a pulsed chicane at the end of Sector 1 compresses the bunch length a second time to the required $30-40 \mu \mathrm{m}$. The emittance of the beam (about $3.5 \mathrm{~mm}$ mrad, normalized) is measured early in Sector 2 with existing profile monitor hardware. The beam is then accelerated to 
Table 4: Parameters of a SLAC SASE demonstration FEL using PALADIN with extra focusing $(\beta=2 \mathrm{~m})$ and stronger fields.

\begin{tabular}{|l|c|c|c|}
\hline Parameter & Low Energy & Medium & High \\
\hline $\mathrm{e}^{-}$energy [GeV] & 0.51 & 1.02 & 1.53 \\
\hline$\gamma$ & 1000 & 2000 & 3000 \\
\hline $\mathrm{e}^{-}$energy spread & 0.02 & 0.02 & 0.02 \\
\hline$\gamma \varepsilon(\mathrm{x}, \mathrm{y})[\mathrm{mm}-\mathrm{mrad}]$ & 3.5 & 3.5 & 3.5 \\
\hline $\mathrm{l}_{\text {peak }}[\mathrm{A}]$ & 2000 & 2000 & 2000 \\
\hline Bunch length [ $\mu \mathrm{m}]$ & 40 & 40 & 40 \\
\hline Undulator period & 0.08 & 0.08 & 0.08 \\
\hline Undulator K & 4.1 & 4.1 & 4.1 \\
\hline Undulator field $[\mathrm{kG}]$ & 5.5 & 5.5 & 5.5 \\
\hline$\lambda$ [nm] & 360 & 90 & 40 \\
\hline Field gain length & 1.05 & 1.6 & 2.2 \\
\hline Saturation length & 11 & 18 & 24 \\
\hline Saturated Power & 4.4 & 5.7 & 6.0 \\
\hline
\end{tabular}

the final energy 500-1500 MeV in Sector 2 and extracted with an existing "pulsed dumper" magnet at linac girder 2-9. Finally, the beam is directed through a short transport line to the PALADIN undulator located in the aisle of the accelerator tunnel. PALADIN would be mounted parallel to the linac and displaced by about $0.75 \mathrm{~m}$. After passing through PALADIN, the spent electron beam is dumped. The emerging photon beam is bent vertically into a $10 \mathrm{~m}$ shaft and analyzed upstairs in the klystron gallery. The estimated parameters for this full scale demonstration experiment are in table 4 with increased focusing in PALADIN. Power saturation can be achieved in all cases with field gain lengths of 1 to $2.2 \mathrm{~m}$. The demonstration would begin with natural focusing in PALADIN but with enhanced fields made by closing the undulator gap. Later, stronger focusing with permanent magnets inserted into the gap providing additional quadrupole terms will lower the electron betatron functions and shorten the field gain lengths by about $30 \%$.

The mechanical and electrical characteristics of the PALADIN undulator, a $25 \mathrm{~m}$ long electromagnetic insertion device used in the first successful demonstration of SASE in the IR range at LLNL, have been described [9]. The structure features an $8 \mathrm{~cm}$ period (two pole-pairs per period), with a parabolic contour ("cutout") machined into the surface of each pole to provide natural sextupole focusing [15]. In the cited experiment, the gap at the beam center line was set at $24 \mathrm{~mm}$, and an on-axis field of $2.5 \mathrm{kG}$ was generated with $120 \mathrm{~A}$ in the field coils, for a $\mathrm{K}$ parameter value of approximately 1.9 .

For the proposed demonstration experiments, optimization studies indicated that saturation in the SASE mode could be obtained with PALADIN over the $120 \mathrm{~nm}-40 \mathrm{~nm}$ range, provided: 1) a $\mathrm{K}$ of 4 , corresponding to an on-axis field of about $5.5 \mathrm{kG}$, could be obtained; and 2) additional focusing, significantly stronger than the natural sextupole focusing provided by the shaped poles, could be provided at the shorter wavelengths. These issues have been studied using a prototype section of PALADIN. By reducing the gap down to approximately $18 \mathrm{~mm}$, the desired $\mathrm{K}$ value can be attained with approximately $160 \mathrm{~A}$ in the field coils without apparent overheating or significant deterioration of the field quality. Regarding enhancement of focusing, a recently proposed scheme utilizing permanent magnet multipole structures constructed out of thin rectangular blucks of PM material [16] has been assessed. As described in more detail in a comnanion paper [17] a $1.5 \mathrm{~cm}$ high quadrupole permanent magnet $(\mathrm{NdFe} / \mathrm{B})$ structure with a $1 \mathrm{~cm}$ gap has been installed into

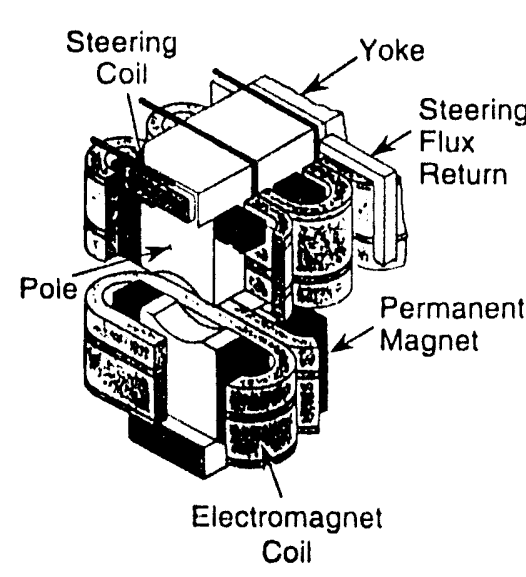

$\rightarrow \infty$

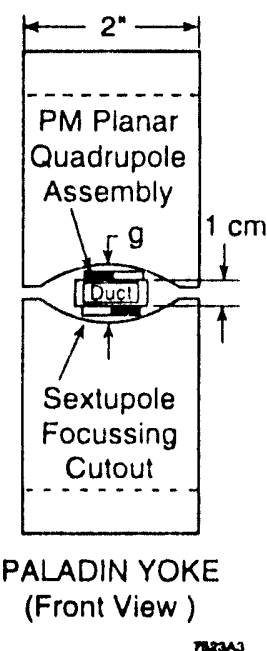

nem
Fig. 6: Planar permanent magnet quadrupole in PALADIN.

PALADIN's central aperture (see fig. 6), and essentially linear superposition of its field with a primary undulator field of $5 \mathrm{kG}$ has been demonstrated. With $2.5 \mathrm{~mm}$ thick permanent magnet blocks, a quadrupole field of approximately $57 \mathrm{~T} / \mathrm{m}$ was measured. Such strong focusing reduces gain lengths so that saturation in the $25 \mathrm{~m}$ length of PALADIN appears achievable at wavelengths down to about $40 \mathrm{~nm}$. 


\section{Demonstration Experiment - Harmonic Generation Examples}

Short wavelength generation via super radiant emission on higher harmonics in a high gain multiple wiggler FEL configuration has been originally proposed some years ago on the basis of 2D numerical simulation [18] and of analytical calculations [19]. The main advantages, in principle, with respect to the SASE configuration are:

1) spectral purity and line width

2) shorter wigglers

3) relaxation of requirements of electron beam quality.

More recently an optimization scheme which uses dispersive sections between different wigglers has been proposed $[20,21]$ on the basis of a simple $1 \mathrm{D}$ calculation but was never tested by $2 \mathrm{D}$ simulations. The $2 \mathrm{D}$ simulations of $[18]$ were assuming a very poor beam quality so that it has

Table 5: Parameters of a SLAC harmonic demonstration FEL using PALADIN with natural focusing.

\begin{tabular}{|c|c|c|c|c|c|}
\hline Case & 1 & 2 & 3 & 4 & 5 \\
\hline$I[A]$ & 2000 & 2500 & 2500 & 2500 & 2000 \\
\hline$\varepsilon_{n}[\mathrm{~mm} \mathrm{mrad}]$ & 3.5 & 4 & 4 & 4 & 3.5 \\
\hline$E[\mathrm{MeV}]$ & 623 & 485 & 485 & 485 & 623 \\
\hline$\Delta \gamma / \gamma[\%]$ & 0.06 & 0.13 & 0.03 & 0.03 & 0.06 \\
\hline$P_{\text {in }}[\mathrm{MW}]$ & 1 & 1 & 0.001 & 0.001 & 1 \\
\hline$L_{w 1}[\mathrm{~m}]$ & 6 & 6 & 11 & 11 & 6 \\
\hline$K_{1}$ & 3.98 & 2.97 & 2.97 & 2.97 & 3.98 \\
\hline$L_{w \cdot 2}[\mathrm{~m}]$ & 9 & 9 & 7 & 10 & 4 \\
\hline$K_{2}$ & 2.63 & 1.85 & 1.85 & 1.27 & 2.63 \\
\hline$L_{\mathrm{n} \cdot 3^{[\mathrm{m}]}}$ & & & & & 8 \\
\hline$K_{3}$ & & & & & 1.57 \\
\hline$P_{\text {out }}[\mathrm{GW}]$ & 3 & 2.4 & 3 & 1.86 & 0.8 \\
\hline$\lambda_{\text {out }}[\mathrm{nm}]$ & 120 & 120 & 120 & 80 & 60 \\
\hline
\end{tabular}
second harmonic of the second section (i.e., the fourth harmonic of the fundamental of the first wiggler) and finally reaching, after $9 \mathrm{~m}$ of the third section, $800 \mathrm{MW}$ of output power at $60 \mathrm{~nm}$ with a total length $0 \mathrm{~m} 19 \mathrm{~m}$ of wiggler.

In all cases one can use the remaining part of the PALADIN wiggler (whose total length is $25 \mathrm{~m}$ ) for tapering and/or for a further harmonic cascade to shorter wavelength. In fact we are studying the possibility of using the harmonic cascade scheme to generate $\sim 4 \mathrm{~nm}$ radiation starting from an input of a shorter wavelength using a dispersive section and a higher energy beam and/or different wiggler.

A detailed discussion of these results showing the radial power on the fundamental and on the harmonics, bunching and energy spread along the wiggler will be presented in a separate paper [14]. 


\section{ACKNOWLEDGMENTS}

This project benefited greatly from a technical review in November 1992. We thank the committee members: I. Ben-Zvi (Chairman), J. Bisognano, L. Elias, J. Goldstein, B. Newnam, K. Robinson, R. Schlueter, A. Sessler, and R. Sheffield. Subsequent discussions with I. Ben-Zvi helped to develop some of the ideas described here.

\section{REFERENCES}

1. C. Pellegrini, J. Rosenzweig, H.-D. Nuhn, P. Pianetta, R. Tatchyn, H. Winick, K. Bane, P. Morton, T. Raubenheimer, J. Seeman, K. Halbach, K.-J. Kim, J. Kirz, "A 2 to 4 nm High Power FEL on the SLAC Linac," International FEL Conference, Kobe, Japan, August 24-28, 1992, and NIM A331, p. 223-227, 1993.

2. H. Winick, K. Bane, R. Boyce, G. Loew, P. Morton, H.-D. Nuhn, J. Paterson, P. Pianetta, T. Raubenheimer, J. Seeman, R. Tatchyn, V. Vylet, C. Pellegrini, J. Rosenzweig, G. Travish, D. Prosıitz, E.T. Schariemann, K. Halbach, K.-J. Kim, M. Xie, "A 2-4 nm Linac Coherent Light Source (LCLS) Using the SLAC Linac," Proceedings of the IEEE 1993 Particle Accelerator Conference, Washington, D.C., May 17-20, 1993.

3. C. Pellegrini, "The SLAC Soft X-Ray High Power FEL", Presented at the 15th International Free Electron Laser Conference, The Hague, Holland, Aug. 23-16, 1993; to be published in the proceedings.

4. J. Seeman, "Linac Coherent Light Source (LCLS) at $2.4 \mathrm{~nm}$ Using the SLAC Linac", Presented at SPIE meeting on "Electron Beam Sources of High Brightness Radiation", San Diego, CA, July 11-16, 1993; to be published in the proceedings.

5. M. Comacchia, H. Winick (editors); Report on the Workshop on Fourth Generation Light Sources, SLAC, Feb. 24-27, 1992, SSRL Repor 92/02

6. I. Ben-Zvi, H. Winick (editors); Report on the Workshop "Towards Shon Wavelength Free Electron Lasers", Brookhaven National Laboratory, May' 21,22, 1993; BNL Report to be printed.

7. J. Rosenzweig and L. Serafini, "Design of a High Brightness RF Photoinjector for the SLAC Linac Coherent Light Source," Proceedings of the IEEE 1993 Particle Accelerator Conference, Washington, D.C., May 17-20, 1993.

8. J. Seeman, "Accelerator Physics of the Stanford Linear Collider and SLC Accelerator Experiments Towards the Next Linear Collider," Advances of Accelerator Physics and Technologies, H. Schopper, Ed. World Scientific, p. 219, 1993.

9. G. A. Deis, A. R. Harvey, C. D. Parkison, D. Prosnitz, J. Rego, E. T. Scharlemann, K. Halbach, "A Long Electromagnetic Wiggler for the PALADIN Free-Electron Laser Experiments," IEEE Trans. Mag. 24(2), 1090(1988).

10. K. Bane, T. Raubenbeimer, and J. Seeman, "Electron Transport of a Linac Coherent Light Source (LCLS) using the SLAC Linac," Proceedings of the IEEE 1993 Particle Accelerator Conference, Washington, D.C., May 17.20, 1993.

11. R. Tatchyn, R. Boyce, K. Halbach, H.-D. Nuhn, J. Seeman, H. Winick, and C. Pellegrini, "Design Considerations for a 60 Meter Pure Permanent Magnet Undulator for the SLAC Linac Coherent Light Source (LCLS)," Proceedings of the IEEE 1993 Particle Accelerator Conference, Washington, D.C., May 17-20, 1993.

12. R. Tatchyn and P. Pianetta, "X-Ray Beam Lines and Beam Line Components for the SLAC Linac Coherent Light Source (LCLS)," Proceedings of the IEEE 1993 Particle Accelerator Conference, Washington, D.C., May 17-20, 1993.

13. K.-J. Kim, M. Xie, E. T. Scharlemann, C. I lllegrini, and G. Travish, "Performance Characteristics, Optimization, and Error Tolerances of a $4 \mathrm{~nm}$ FEL Based on the SLAC Linac," Proceedings of the IEEE 1993 Particle Accelerator Conference, Washington, D.C., May 17-20, 1993.

14. R. Bonifacio, L. De Salvo, P. Pierini, N. Piovella, C. Pellegrini, submitted to the Int. FEL Conf. '93, The Hague, Holland, Aug 23-26 (1993).

15. E. T. Scharlemann, "Wiggler plane focusing in linear wigglers," J. Appl. Phys. 58(6), 2154(1985).

16. R. Tatchyn, "Planar Permanent Magnet Multipoles for Particle Accelerator and Storage Ring Applications," SLAC. PUB-6186, May 1993.

17. J. Cobb and R. Tatchyn, "Tests of Planar Permanent Magnet Multipole Focusing Elements," - elsewhere this conference.

18. R. Bonifacio, L. De Salvo, P. Pierini, E.T. Scharlemann, Nucl. Inst. Meth. A296 (1990) 787.790

19. R. Bonifacio, L. De Salvo, P. Pierini, Nucl. Instr. Meth. A293 (1990) 627

20. I. Ben-Zvi, L.F. Di Mauro, S. Krinsky, M.G. White, L.H. Yu, Nucl. Instr. Meth, A304, (1991) 181

21. R. Bonifacio, R. Corsini, P. Pierini, Phys. Rev. A, vol. 45, n.6 (1992) 4091

22. P. Pierini, L. De Salvo, R. Bonifacio, submitted to the Int. FEL Conf. '93, The Hague, Holland, Aug 23-26 (1993). 


\section{DISCLAIMER}

This report was prepared as an account of work sponsored by an agency of the United States Government. Neither the United States Government nor any agency thereof, nor any of their employees, makes any warranty, express or implied, or assumes any legal liability or responsibility for the accuracy, completeness, or usefulness of any information, apparatus, product, or process disclosed, or represents that its use would not infringe privately owned rights. Reference herein to any specific commercial product, process, or service by trade name, trademark, manufac: turer, or otherwise does not necessarily constitute or imply its endorsement, recommendation, or favoring by the United States Government or any agency thereof. The views and opinions of authors expressed herein do not necessarily state or reflect those of the United States Government or any agency thereof. 

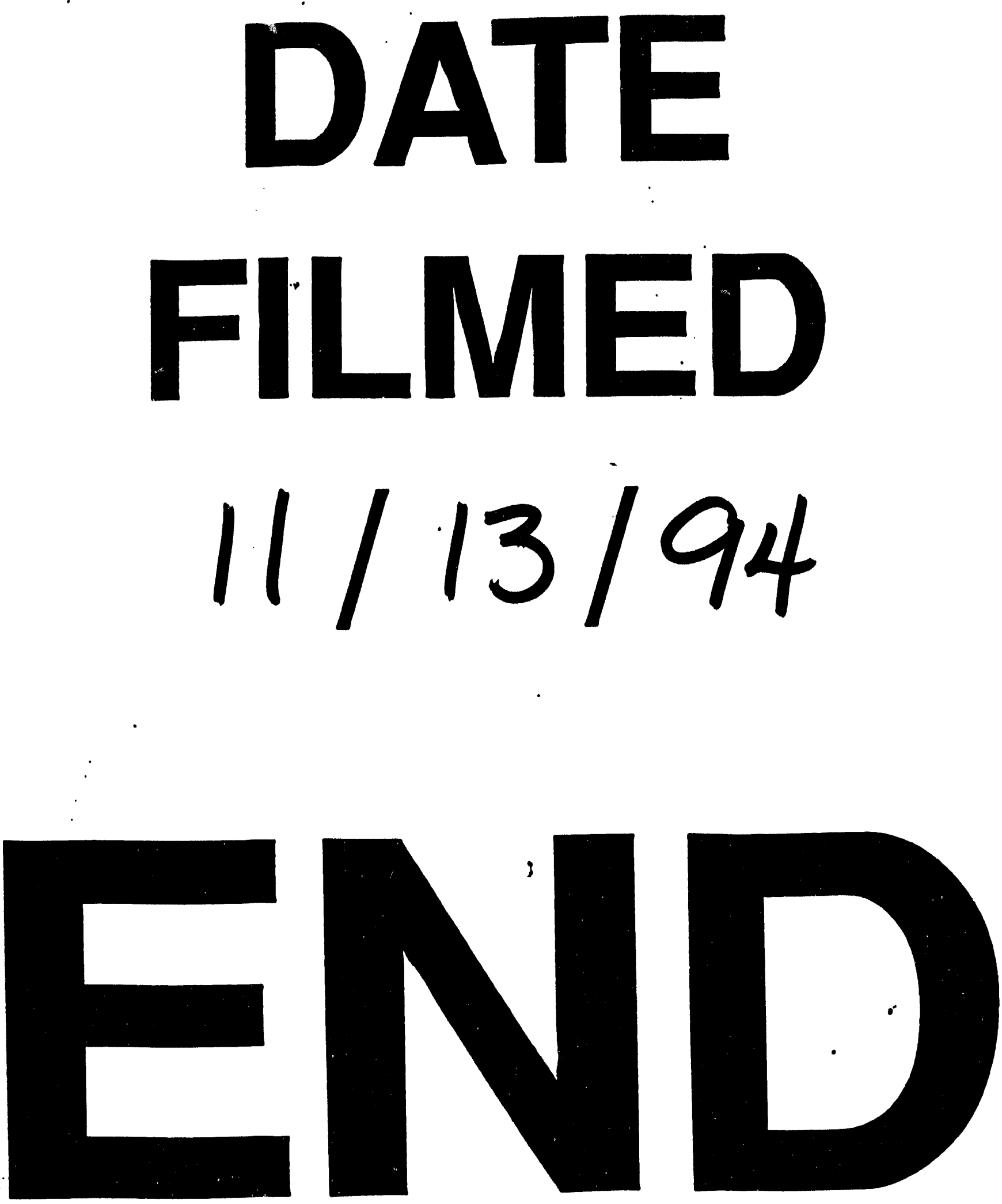
